\title{
LA PERSONALIDAD DEL EMBRIÓN: LA FILOSOFÍA ANTE LOS LÍMITES DE LA IMAGINACIÓN ${ }^{1}$ THE EMBRYO'S PERSONALITY: PHILOSOPHY IN DEALING WITH THE LIMITS OF THE IMAGINATION A PERSONALIDADE DO EMBRIÃO: A FILOSOFIA ANTE OS LIMITES DA IMAGINAÇÃO
}

Richard Stith ${ }^{2}$

DOI: $10.5294 /$ pebi.2017.21.1.11

En ocasiones, nuestras intuiciones favorecen la posición provida y, en otras, se oponen a ella. Un video de ultrasonidos de un bebé no nacido chupándose el dedo defiende la causa contra el aborto de un modo que apenas necesita el apoyo de la razón; pero un cigoto fotografiado inmediatamente después de una concepción in vitro no es tan fácilmente reconocible como un ser humano o una persona.

Los provida asumen habitualmente que la ciencia moderna ha superado esta dificultad; ya con la primera prueba clara de fertilización de un óvulo, en 1830, y con el punto de vista científico aceptado universalmente de que la vida de los seres humanos es un continuo desde la concepción hasta la muerte. Hoy en día, casi nadie cree más en la noción aristotélica de que el embrión es solo un ente (digamos) "en construcción”, un ente que se convierte en ser humano durante los primeros meses de gestación gracias al alma "constructora" del

1 Este texto es una adaptación de un reciente artículo del autor: "Construction vs. Development: Polarizing Models of Human Gestation”, publicado en Kennedy Institute of Ethics Journal, en 2014, volumen 24, número 4, páginas 345-384. Se presentó en las $\mathrm{X}$ Jornadas de la Asociación Española de Personalismo (Madrid, 5 de mayo de 2016). Fue traducido por Alfonso Ballesteros.

2 orcid.org/0000-0002-7329-3305. Valparaiso University, Indiana, Estados Unidos. richard.stith@valpo.edu padre (traída por su semen), un proceso que culmina con la inserción de un alma racional propia del feto en algún momento a mitad del embarazo. Esta visión, basada en la construcción, ha quedado desplazada por el reconocimiento de que el conceptus es un ser que no se construye, sino que se desarrolla a sí mismo, de forma continuada, desde su comienzo hasta su madurez.

Sin embargo, el conocimiento científico de que cada uno de nosotros comenzó con la concepción no ha sido suficiente para convencer a mucha gente de que el embrión ya es uno de nosotros. El periodista Michael Kinsley ha escrito en el Washington Post a favor de la investigación que mata embriones humanos (para obtener células madre) y ha expresado ahí su asombro ante los que se oponen a este tipo de investigación:

No comparto, ni puedo comprender, la convicción de que un punto microscópico - tan inconsciente como una roca, más primitivo que un gusanotiene los mismos derechos que cualquiera que lee este artículo [...]. La sinceridad moral no merece ser tenida en consideración si se basa en una ignorancia voluntaria y en una indiferencia ante la lógica. (1)

Desde luego, la intuición de Kinsley de que el embrión es "tan inconsciente como una roca" se debe a su propia 


\title{
CUANDO SE CONTEMPLA UNA FOTOGRAFÍA DE UN EMBRIÓN HUMANO, CONSIDERANDO
}

\author{
ASÍ NADA MÁS QUE SU APARIENCIA ACTUAL, ES MUY FÁCIL NO TENER EN CUENTA SU \\ AUTODESARROLLO, AUNQUE YA ESTÁ EN MARCHA, PORQUE LA FOTOGRAFÍA NO PUEDE \\ REPRESENTAR LA AUTODIRECCIÓN INTERIOR DEL EMBRIÓN EN CRECIMIENTO
}

inconsciencia acerca del autodesarrollo del embrión y su relación con el entorno. Jon Shields ha aclarado bien esta falta:

[Decir que] los embriones son simples "grupos de células" [...] tiende a oscurecer la verdad científica misma. Esta caracterización sugiere que el embrión no es biológicamente diferente de lo que podemos encontrar bajo nuestras uñas si arrancamos un poco de nuestra piel [...]. Se deduce erróneamente que carecen de coherencia, integridad y de un desarrollo propio como organismos. (2)

¿Debemos responder entonces que Kinsley y otros defensores de la investigación con embriones y del aborto en una fase temprana $-\mathrm{O}$, al menos, aquellos con un mínimo de educación científica - tienen que estar actuando de mala fe? ¿Pretenden ellos que el embrión carece de identidad humana individual solo porque no desean ser vistos atacando los principios, básicos y ampliamente compartidos, que afirman la dignidad, igualdad o inviolabilidad de todos los seres humanos? Una explicación así es demasiado simple. Se desmiente por el asombro mismo que Kinsley espera compartir con sus lectores. De hecho, la acusación de mala fe ignora la barrera imaginativa que muchos o todos nosotros tenemos para reconocer al embrión como el ser humano, que ya es pero que todavía no parece ser.
Cuando se contempla una fotografía de un embrión humano, considerando así nada más que su apariencia actual, es muy fácil no tener en cuenta su autodesarrollo, aunque ya está en marcha, porque la fotografía no puede representar la autodirección interior del embrión en crecimiento. El embrión en la foto parece ser solo un conjunto inerte de células, porque su futuro está oculto. Debido a que una entidad que tuviera como su estado natural y final solamente características embrionarias no sería calificada como "ser humano", tiene mucho sentido intuir que la entidad en la fotografía no es humana. El conocimiento científico de su capacidad interior podría no ser suficiente para superar esta intuición, ya que es difícil imaginar una naturaleza (o diseño) completamente oculta a la vista.

Dicho de otra manera, es muy difícil imaginar la transformación o metamorfosis biológica. Es decir, es difícil reconocer la continuidad de la identidad a través de un cambio aparentemente sustancial en la forma. Es difícil ver una oruga como una mariposa en desarrollo, por ejemplo. Pero hay una dificultad aún más grande. Más allá de los problemas que podemos tener en imaginar la metamorfosis, es casi imposible imaginar una oruga como una mariposa particular o individual en su proceso de desarrollo. Sin embargo, así es como tenemos que imaginar a los embriones si queremos entender plenamente su desarrollo como seres humanos. Habitualmente, pensamos en otras criaturas de manera 
genérica; simplemente como un tipo de insecto, por ejemplo, pero pensamos en los seres humanos como personas, es decir, como individuos específicos, con características particulares y concretas (aunque pueden ser desconocidas por nosotros en un determinado momento). Ya que al embrión en la foto no se le pueden atribuir características específicas — salvo arbitrariamente- es difícil pensar en este como un individuo en desarrollo. El hecho científico de que "Este embrión llegará a ser un humano adulto" es demasiado abstracto. Todos hemos visto muchas mariposas genéricas, pero ninguno de nosotros ha visto nunca un ser humano adulto genérico (es decir, no individualizado).

Por lo tanto, los provida honestos consigo mismos deben admitir que existen límites a nuestra imaginación ontológica, que son una gran barrera para lograr el total respeto (3) para la vida humana, especialmente en el periodo inicial del embarazo, cuando el no nacido todavía carece de un aspecto parecido al resto de nosotros (4). Sin embargo, hay modos de superar estos límites y aumentar la capacidad imaginativa de nuestro entendimiento.

Aunque podemos tener una considerable dificultad en reconocer la continuidad futura de un ser, poca o ninguna dificultad estriba en reconocer la identidad (a pesar de la transformación) cuando miramos a su pasado. Podríamos dudar de que un nuevo brote, o incluso una parra que

todavía no da fruto, fuera realmente una tomatera; pero desde el momento en que tiene tomates, sabemos que ha sido siempre una tomatera. Podemos dudar de que los embriones sean personas, pero si miramos hacia nuestro pasado o el de nuestros vecinos, nos damos cuenta de que tanto ellos como nosotros una vez fuimos embriones. En un primer momento, un embrión en una fotografía puede no parecer más que un grano de arena, pero si la foto del embrión hubiera sido tomada hace veinte años, justo después de que nuestra amiga María fuera concebida in vitro, podríamos decirle a María con clara razón: “Mira, María, jeres tú!".

\section{TENER UNA CONSIDERABLE}

DIFICULTAD EN RECONOCER

LA CONTINUIDAD FUTURA

DE UN SER, POCA O

NINGUNA DIFICULTAD

ESTRIBA EN RECONOCER LA

IDENTIDAD (A PESAR DE LA

TRANSFORMACIÓN) CUANDO

MIRAMOS A SU PASADO
En los debates sobre los inicios de la vida humana los pensadores de ambas posiciones (a favor y contra el aborto) se han puesto de acuerdo en que la identidad de la vida a través del tiempo — y la dignidad que la acompaña— se vuelve mucho más convincente cuando miramos hacia el pasado. El filósofo Jeffrey Reiman, un defensor del aborto, señala (con tristeza) que:

[... tendemos a entender la identidad personal retrocediendo hasta el feto, y la identidad personal tiene connotaciones de identidad moral más allá de la mera identidad física [...]. Como es muy natural para nosotros pensar de ese modo, esa “atribución retroactiva de la personalidad” es [para Reiman] la fuente de confusión más grande en el debate sobre el aborto. (5) 
Un filósofo contrario al aborto, Oliver O’ Donovan, subraya el mismo punto cuando escribe: "Conocemos como personas a los no nacidos cuando son niños..."3 (6). Conocemos a los embriones como personas cuando conocemos a los niños que comenzaron su existencia como embriones.

Aquellos que son contrarios a la investigación con células madre embrionarias - y al aborto en una fase tempranahan insistido a menudo en la continuidad de la identidad desde un punto de vista retrospectivo. Hace algunos años, la Conferencia de los Obispos Católicos de Estados Unidos difundió un anuncio con una foto de un bebé recién nacido y debajo: "Hace 270 días Joshua era solo un embrión”. El texto continuaba enfatizando que "las células madre embrionarias [...] tienen un alto precio: se obtienen destruyendo un embrión humano con vida. Un embrión como Joshua hace 270 días”. En 2010, un grupo de irlandeses contrario a la investigación destructora de embriones colgó carteles con fotos de muchas fases de la vida, desde la embrionaria hasta la anciana, y las palabras estas: “TÚ. YO. TODO EL MUNDO. TODOS NOSOTROS NO SOMOS MÁS QUE EMBRIONES YA CRECIDOS (“GROWN-UP”)".

Estos argumentos de los oponentes a la investigación que destruye embriones son fundamentalmente cognitivos, no emocionales. Son intentos de agarrar y captar mentalmente el desarrollo humano, tal y como es conocido por la ciencia moderna; intentos de superar la dificultad de imaginar que un organismo realmente pequeño puede, con el tiempo, manifestarse como un individuo humano plenamente maduro. Ellos miran

3 Énfasis en el original.

4 Mayúsculas en el original. primero hacia el pasado — desde los seres humanos desarrollados, donde la continuidad de la identidad es personal y fácil de ver-y a continuación miran hacia adelante — desde los embriones todavía no desarrollados- para ver cómo estos se encuentran en camino de mostrarse el tipo de personas que conocemos y amamos. Esa intuición inicial que mira hacia el pasado no solo es compatible con el conocimiento científico moderno, sino que depende de este. Solo a causa de este conocimiento podemos señalar una vieja foto y decir: "Esa eras tú, María, recién concebida”. Alguien que todavía pensara con Aristóteles que María comenzó a existir a mitad del embarazo, cuando un alma racional entró en un feto infrahumano previamente construido, no podría señalar la foto y decir: "Ésa eras tú, María”.

Si pudiéramos ver de alguna manera las características futuras de un embrión humano todavía no desarrollado, nuestra mirada intuitiva hacia el futuro podría, por sí misma, aproximarse más a nuestra mirada intuitiva hacia el pasado. Consideremos este ejemplo: supongamos que una mujer está de viaje con su marido en Chiapas, México, y ella hace una foto con su vieja cámara Polaroid. (Recuérdese que, en unos pocos minutos, después de cada disparo de la Polaroid la impresión final va a desarrollarse en un envoltorio. Después de esperar y separarla del envoltorio, la imagen puede ser examinada y mostrada a otros.) Supongamos también que la foto que ella ha hecho es de algo que se considera único y valioso, igual que decimos que cada individuo humano es único y valioso. Digamos que era de un jaguar saliendo de la jungla solo por un segundo, algo que difícilmente volvería a ocurrir durante su viaje. Pero el marido, por precipitación, saca el envoltorio de la cámara y lo separa demasiado rápido de la foto, de manera que detiene el desarrollo de la foto en una fase temprana de manera permanente. Como la 
foto de su jaguar ha desaparecido para siempre — las viejas Polaroid no guardan negativo ni copia alguna-, naturalmente ella se enfada con él. ¿Podría ser una buena defensa para él decirle a ella: "Mira, cariño, realmente no he hecho demasiado daño. Tu foto todavía era una mancha marrón cuando la estropeé. Seguro que no te importan demasiado las manchas marrones, ¿no?’?

Este argumento sería completamente inaceptable para ella. Ni siquiera lo entendería; le parecería que su marido decía algo no inteligible. Ella pensaba que tenía una foto de un jaguar no de una mancha marrón. Las sustancias químicas no necesitaban más que algo de tiempo para hacerse visible como foto.

Así es como un futuro concreto e individual ya conocido permite que la continuidad de la identidad, a través de los cambios, sea algo completamente evidente a nuestra intuición.

El filósofo africano Kwame Anthony Appiah ha dado un gran paso adelante para imaginar el futuro concreto e individualizado de un feto no nacido al escribir que quienes debaten sobre el aborto deben tener en cuenta que "esos fetos muertos podrían haber sido... amigos de sus hijos" (7). La capacidad de ser amigo de otro es un rasgo universal de los seres humanos; pero, al mismo tiempo, es un rasgo que personaliza, ya que todo amigo es un individuo único. Decir que un embrión podría haber sido un amigo permite imaginarlo como ser humano individual, aunque todavía no se sabe nada de él como ser humano individual.

Si pudiéramos analizar la estructura genética de un embrión y concluir: "Este embrión llegará a ser una mujer asiática con un considerable talento artístico", la

\section{Así es COMO Un FUTURO CONCRETO E INDIVIDUAL YA CONOCIDO PERMITE QUE LA CONTINUIDAD DE LA IDENTIDAD, A TRAVÉS \\ DE LOS CAMBIOS, SEA ALGO COMPLETAMENTE EVIDENTE A NUESTRA INTUICIÓN}

continuidad de la identidad humana podría convertirse en algo todavía más intuitivo, y más aún si un computador pudiera algún día extraer su imagen de su ADN y mostrarnos su aspecto —incluso su rostro- como un bebé recién nacido, una niña pequeña, una adolescente o una adulta. Las opiniones opuestas a la violencia contra los seres humanos en fase embrionaria, entonces, podrían surgir con más facilidad. Emmanuel Levinas (8) ha sugerido que es precisamente el rostro del Otro lo que nos obliga, y los estudios neurológicos del comportamiento de los niños pequeños apoyan estas observaciones. Las imágenes ultrasónicas de los rostros de fetos (con ojos todavía cerrados) ya han tenido como consecuencia un mayor respeto hacia la vida prenatal, pero mucho más grande podría ser el efecto de ver un rostro con los ojos abiertos. ¿Podríamos "mirar a un embrión a los ojos" y decidir fácilmente aniquilarlo?

La posibilidad técnica de dichas imágenes parece estar ya a la puerta. Un reportaje titulado "Construyendo un rostro... con ADN" ("Building a Face and a Case on DNA") era el titular en la sección de ciencia del New York Times del 24 de febrero de 2015. Los investigadores forenses ya habían utilizado "el fenotipo extraído del ADN" para desarrollar perfiles visuales aproximados de los sospechosos, especialmente cuando nadie ha presenciado el delito; pero se han encontrado restos de ADN. Como señala el New York Times, este uso del ADN 
para "producir" rostros tiene sentido, porque sabemos todos que los gemelos idénticos son muy similares de cara y que las personas habitualmente se parecen a los miembros de sus familias. Esto hace evidente la gran influencia de la genética en el rostro del ser humano. Hay ejemplos en el periódico de rostros generados por computador, cuyo parecido con los rostros actuales es impactante, aunque todavía no perfecto. Los investigadores Mark Shriver y Peter Claes siguen aumentando la precisión añadiendo todavía más variables genéticas.

Si el ADN adulto puede lograr la obtención de un boceto del rostro de una persona, seguro que el ADN gestacional — obtenido de un modo no perjudicial; por ejemplo, de la sangre materna - podría usarse del mismo modo para hacer un boceto del rostro futuro de un niño no nacido, porque el contenido del ADN de nuestras células casi no cambia a lo largo de nuestras vidas.

Podríamos estar a punto de otro gran avance tecnológico, como el de los ultrasonidos, que nos ayuda a superar la barrera imaginativa que nos impide reconocer a las personas humanas en sus primeras fases de desarrollo.

\section{REFERENCIAS}

1. Kinsley M. False dilemma on stem cells. Washington Post. 2006 julio 7.

2. Shields J. The stem cell fight. Soc Sci Mod Soc. 2007;44:18-21.

3. Stith R. La prioridad del respeto: cómo nuestra humanidad común puede fundamentar nuestra dignidad individual. Persona y Derecho. 2010;62:181-210.

4. Stith R. Construction vs. development: Polarizing models of human gestation. Kennedy Institute of Ethics Journal. 2014;24(4):345-84.

5. Reiman J. Abortion and the ways we value human life. Lanham: Rowman \& Littlefield; 1999.

6. O'Donovan O. Again, who is a person? In: Lammers SE, Verhey A, editors. On moral medicine. Grand Rapids: Eerdmans; 1998. p. $384-86$.

7. Appiah KA. Cosmopolitanism: Ethics in a world of strangers. Nueva York: W. W. Norton; 2006.

8. Levinas E. Totality and infinity: an essay on exteriority. Pittsburgh: Duquesne University Press; 1969. 